\title{
Applications of Click Chemistry in Radiopharmaceutical Development
}

\author{
Joseph C. Walsh and Hartmuth C. Kolb*
}

\begin{abstract}
Dedicated to Professor Daniel Belluš on the occasion of his 70th birthday
Abstract: Click chemistry, a concept that employs only practical and reliable transformations for compound synthesis, has made a significant impact in several areas of chemistry, including material sciences and drug discovery. The present article describes the use of click chemistry for the development of radiopharmaceuticals. Target templated in situ click chemistry was used for lead generation. The 1,2,3-triazole moiety was found to improve the pharmacokinetic properties of certain radiopharmaceuticals. The reliable $\mathrm{Cu}(\mathrm{l})$-catalyzed click reaction was employed for radiolabeling of peptidic compounds without the need for protecting groups. In summary, the click chemistry approach for the discovery, optimization and labeling of new radiotracers, represents a very powerful tool for radiopharmaceutical development.
\end{abstract}

Keywords: Biomarker · Carbonic anhydrase · Click chemistry · Hypoxia · Integrins ·

Positron emission tomography $\cdot$ Radiopharmaceutical

\section{Introduction}

Click chemistry is a modular approach to chemical synthesis whose aim is to quickly prepare synthetically accessible molecules rather than laboring over more synthetically demanding compounds by utilizing only the most practical and reliable chemical transformations. ${ }^{[1,2]}$ Click chemistry transformations are wide in scope, high yielding, produce inoffensive byproducts that are easily separable and maintain stereo-specificity. They employ readily available starting materials and reagents, use no solvent, or only benign solvents that are easily removed, and the reaction conditions and product isolation are simple.[1] Although click chemistry encompasses a wide array of functional groups and varied chemical transformations, the coppercatalyzed 1,2,3-triazole formation from azides and terminal alkynes is the most commonly used click reaction. ${ }^{[3-9]}$ High yields, benign solvents, tolerance to other functional groups and specificity have allowed this copper-catalyzed click reaction to be employed in many different aspects

\footnotetext{
${ }^{\star}$ Correspondence: Dr. H. Kolb

Siemens Molecular Imaging Biomarker Research

6100 Bristol Parkway

Culver City, CA 90230

USA

Tel.: +1 3108461674

Fax: +1310 5689491

E-mail: hartmuth.kolb@siemens.com
}

of chemistry, including medicinal, biomedical and materials chemistry.

Medicinal chemistry had incorporated triazoles into their pharmacophore toolkit long before the discovery of the $\mathrm{Cu}$-catalyzed click reaction. ${ }^{[10,11]}$ The triazole moiety is also present in a commercially available $\beta$-lactamase inhibitor, tazobactam, as well as other triazole based $\beta$-lactamase inhibitors whose high potencies are credited to the triazole functional group. ${ }^{[12,13]}$ Triazoles have been described as non-traditional amide bioisosteres and are typically substituted for potentially labile functional groups such as esters or amides. ${ }^{[10]}$ Click chemistry has been demonstrated to be an efficient tool for in situ library screening as well as discovery high affinity ligands using in situ click chemistry. ${ }^{[14-19]}$ One discipline that has recently embraced the use of click chemistry is the field of radiopharmaceutical development, and in particular radiopharmaceuticals used for positron emission tomography (PET) imaging.

Over the past 10 years PET has evolved from a research tool to a commonly applied clinical imaging diagnostic test. At the heart of PET imaging are isotope-labeled molecular probes that undergo specific biological transformations (e.g. enzymatic transformation, such as phosphorylation) or that bind to biomolecules with high specificity and affinity.[20] The exact location of the transformed or bound molecular probes can then be determined by detecting the gamma-rays' two $511 \mathrm{keV}$ photons, formed by positron/electron annihilation, that emanate from them. The PET images easily reveal the probes' ability to localize at the desired biological target and, in addition, allow bio- distribution and excretion pathways to be determined.[21-23] The most commonly used positron-emitting isotopes are ${ }^{11} \mathrm{C}(\mathrm{t} 1 / 2=$ $20.4 \mathrm{~min})$ and ${ }^{18} \mathrm{~F}(\mathrm{t} 1 / 2=109.8 \mathrm{~min})$. They can be readily introduced into small, 'druglike' molecules, which are able to penetrate cell walls and the blood brain barrier, and allow intracellular and neurological targets to be imaged. Thus, PET imaging not only enables disease diagnosis in a clinical setting, but also supports the development of new therapeutic drugs by allowing receptor occupancy and pharmacokinetic properties to be evaluated in vivo.

Currently, the vast majority of PET scans are performed with just one imaging probe, the glucose analog $2-\left[{ }^{18} \mathrm{~F}\right]$-fluoro2-deoxyglucose (FDG), which measures glucose metabolism. FDG is transported into cells through glucose transporters (GLUT-1-5), ${ }^{[24,25]}$ where its $\mathrm{O}(6)$ phosphorylation through hexokinase prevents the charged metabolite from exiting cells. The resulting accumulation of 6-phosphoFDG allows cell types with enhanced glucose metabolism to be diagnosed. Due to the Warburg effect, ${ }^{[26,27]}$ PET imaging with FDG is highly successful for the detection and staging of malignant tumors, which typically have a considerably increased glucose metabolism. FDG-PET is also used for the assessment of myocardial viability and the early diagnosis of neurodegenerative disorders. ${ }^{[28]}$ Only a limited number of other imaging probes are being used in clinical research. They target tumor cell proliferation, tumor hypoxia, amyloid-beta plaques in Alzheimer's disease, the dopaminergic and serotoninergic nervous system as well as somatostatin and integrin receptors. Despite 
the recent development of novel PET imaging applications, ${ }^{[29-32]}$ the overall number of clinically-used molecular imaging probes is still small, when compared to the large number of disease-related biological targets that have been identified in the recent years. Thus, new PET probes are needed to fulfill the promise of molecular imaging, to assist in diagnosis of disease and therapy monitoring, and to support therapeutic drug development.

In some aspects, radiotracer development mirrors that of drug development: leads must be discovered, tested and validated in vivo prior to clinical development. ${ }^{[33-35]}$ The presence of a radioisotope makes certain in vivo tests simpler, such as the determination of the pharmacokinetics and metabolism. However, there are also complications, since the relatively short half-lives of PET radioisotopes limit the functional use of the tracer. Tracers must not only be freshly produced in relatively close proximity to the place of use, but their pharmacokinetic and dynamic properties must be compatible with this compressed timeframe, which limits the use to about three half-lives. Therefore, the tracers should be optimized for fast and efficient clearance, high and specific target uptake (typically low nanomolar or better affinity for the target) and reasonable biostability. ${ }^{[36]}$ From a synthesis perspective, the short halflives require that the tracer production be rapid (within two half-lives), ${ }^{[37]}$ the purification be efficient and the formulation be suitable for mammalian imaging. [38]

Click chemistry is ideally suited for radiotracer development and production. It can be employed for several aspects of the development phase including initial lead discovery and optimization of pharmacokinetic properties. It also makes radiolabeling very efficient, so that candidate PET imaging tracers can readily be prepared and tested.

\section{The Use of in situ Click Chemistry for PET Radiotracer Development}

Traditionally, PET probe development involved the replacement of a hydroxyl or an alkyl group or a hydrogen atom in a protein ligand or enzyme substrate by ${ }^{18} \mathrm{~F}$. This substitution can change the molecule's pharmacokinetic properties in an unpredictable, potentially detrimental fashion. In certain cases it may, therefore, be prudent to use a de novo approach for development of PET tracers, by incorporating fluorine already during ligand discovery. In situ click chemistry, a kinetically controlled variant of target-guided synthesis (TGS), is very well suited for the de novo discovery of PET imaging agents. In the first step, ${ }^{19} \mathrm{~F}$-labeled compounds that display a high affinity to their biological target that template their

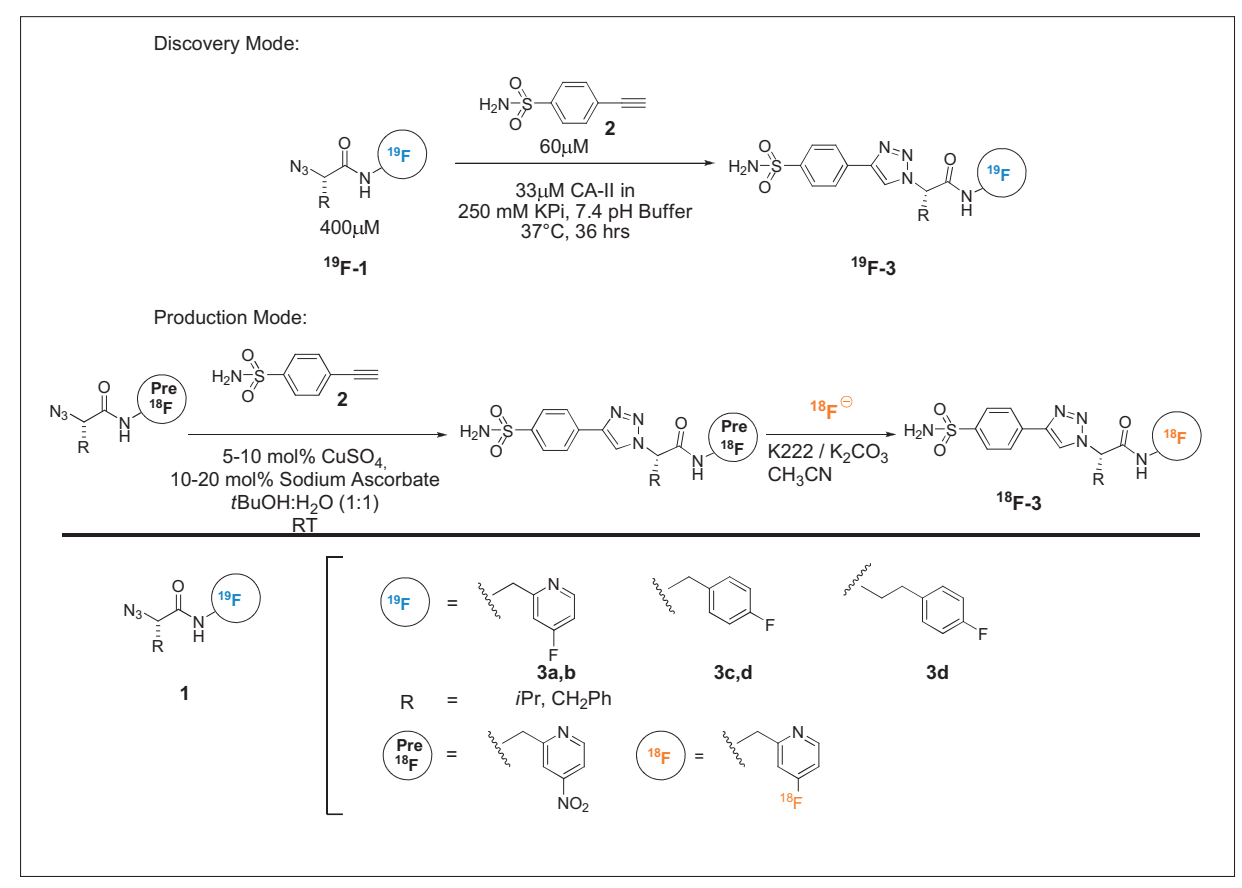

Scheme 1. Discovery and production modes used for the identification and preparation of CA-II PET imaging agents.

formation are identified. In the second step, a candidate PET tracer is synthesized, with minimal changes in binding and physicochemical properties, by using the positronemitting ${ }^{18} \mathrm{~F}$ isotope instead of ${ }^{19} \mathrm{~F}$. In a third step, the candidate probe is subjected to biological in vitro and in vivo tests to confirm its specificity for the desired target.

This new process has been validated with CA-II as the biological target, ${ }^{[17]}$ whose in vivo expression is up-regulated in pancreatic and nervous system tumors, yet down-regulated in non-small cell lung tumors, a difference that may prove to have significant clinical benefit. ${ }^{[39,40]}$ The initial stages of the discovery process by in situ click chemistry began with a small library of ${ }^{19} \mathrm{~F}$-containing azido acid derived fragments ${ }^{19}$ F-1 (Scheme 1) and ethynylbenzenesulfonamide (2) as the anchor molecule $\left(\mathrm{K}_{\mathrm{d}}=\right.$ $37 \mathrm{nM})$. The latter had previously yielded sub-nanomolar CA-II inhibitors through target-guided inhibitor formation. ${ }^{[17]}$ All reaction mixtures were analyzed for the presence of triazoles $\mathbf{3}$ by HPLC using mass spectrometric detection (LC/MS). Because the in situ click chemistry-derived high affinity CA-II ligands already contain fluorine, conversion to their ${ }^{18} \mathrm{~F}$-fluoride analogs can be accomplished without changing the chemical or biological characteristics of the compound, making probe generation predictable and reliable. In contrast, modification of existing drugs for PET imaging is associated with a high risk of changing target affinity and pharmacokinetics. ${ }^{[41]}$

Five azide fragments ${ }^{19} \mathbf{F}-1$ yielded triazoles ${ }^{19} \mathbf{F}-3$ (Scheme 1) in the presence of CA-II, while no products were formed in the presence of the active site blocker Eth- oxzolamide or if BSA was used instead of CA-II. Only 1,4-disubstituted triazoles ('anti-triazoles') were formed by CA-II, further corroborating the active participation by the enzyme, since the protein-free, thermal [3+2] cycloaddition reactions between azides and acetylenes usually give syn/anti mixtures. These results are in good agreement with previously published observations. ${ }^{[17]}$ All five in situ click chemistry hits proved to be highly potent, sub-nanomolar CA-II ligands as revealed by the DNSAbased fluorescence binding assay. ${ }^{[17,42,43]}$

The fluoropyridine derivative ${ }^{\mathbf{1 8}} \mathbf{F}-\mathbf{3 b}$, whose ${ }^{19} \mathrm{~F}$-variant displayed a CA-II $\mathrm{Kd}$ of $0.5 \mathrm{nM}$, was selected for in vivo PET studies in mice (Fig. 1).

The biodistribution of ${ }^{\mathbf{1 8}} \mathbf{F}-\mathbf{3 b}$ was determined through PET studies in severe combined immunodeficient (Scid/Scid) mice (n $=3$ ). Both the PET scans and the radioactivity measurements revealed that the tracer was accumulated mainly in the lungs, heart, kidneys and blood. The dynamic PET data and radioactivity measurements showed that the tracer levels in the blood remained almost constant over a period of 2.5 hours, and over $90 \%$ of the total radioactivity was found in the blood cells. Tracer uptake was blocked by the non-radioactive CA-II inhibitor Ethoxazolamide, demonstrating that the tracer's uptake in blood cells was due to CA-II binding. The tracer biodistribution correlates well with known CA-II expression and distribution in tissues ${ }^{[44-46]}$ suggesting that the in situ click chemistry-derived CA-II ligand is a good PET molecular imaging probe for the in vivo determination of CA-II expression. This is the first application of in situ click chemistry in the devel- 


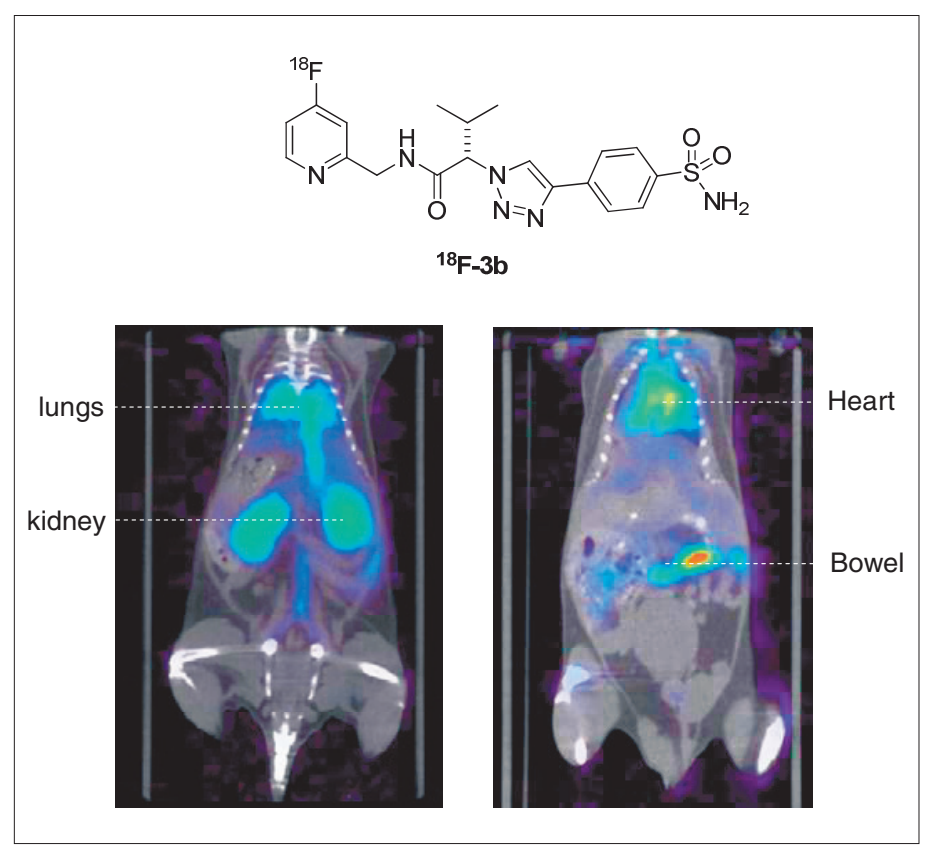

Fig. 1. PET/CT images obtained 60 min. post injection with ${ }^{18} \mathrm{~F}-\mathbf{3 b}$.

opment of small molecule-based molecular imaging probes.

\section{Use of a Click Chemistry- derived Triazole to Optimize Pharmacokinetic Properties}

In the early stages of tracer development, the pharmacokinetic profile is usually less than optimal: the tracer's clearance might be slow relative to target uptake and, in addition, the tracer may non-specifically localize across a large section of the subject, such as the midsection which contains both the liver and gastrointestinal tract (GI). We have found that the 1,2,3-triazole moiety often has a very beneficial influence on the pharmacokinetic properties of a candidate tracer. It has the propensity to increase the washout efficiency, to decrease the liver and GI tract uptake, as well as to shift the clearance pathway from the liver to the kidneys. This allows for earlier scan times, potentially higher target to background ratios and reduced non-target related uptake in the liver/ gut region. In addition, if a tracer spends a minimal amount of the time in the liver, it is less likely to be degraded by liver enzymes.

We have incorporated a 1,2,3-triazole moiety into a generic hypoxia-based pharmacophore, a 2-nitroimidazole, for the purposes of developing an improved hypoxia imaging agent. Tumor oxygenation has been linked to response to radiotherapy and tumor recurrence or progression. ${ }^{47-49]}$ Consequently, the determination of tumor hypoxia (oxygen starvation) is of great value to radiologists, since it may predict a patient's treatment response and since it may guide radiation therapy. ${ }^{[47,48]}$ Hypoxia imaging may also allow patient selection for hypoxia-activated drugs (e.g. Tirapaza- mine). ${ }^{[50]}$ There are other potential applications for identifying hypoxic tissue, outside of cancer, as in the cases for heart attack (identifying ischemic, hypoxic, yet viable heart tissue) and stroke (identifying hypoxic, yet viable brain tissue). ${ }^{[51,52]}$

The putative mechanism of uptake of 2-nitroimidazole-based hypoxia tracers is described below (Scheme 2). ${ }^{[53]}$ The tracer crosses the cell membrane and undergoes bioreduction by intracellular nitroreductases. Under normoxic conditions, the tracer is reoxidized by $\mathrm{O}_{2}$ back to the neutral nitro moiety and the tracer is free to leave the cell. However, under hypoxic conditions, the bioreduced tracer undergoes further reduction and begins to undergo further decomposition and intracellular binding to

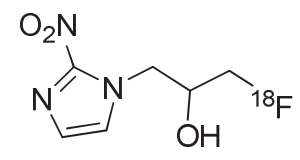

F-MISO macromolecules, hence trapping it within the hypoxic environment. The rate of washout of the tracer in normoxic tissues has been linked to the $\log \mathrm{P}$ of the tracer: the higher the $\log \mathrm{P}$, the slower the background clearance. ${ }^{[54]}$

Of the various existing 2-nitroimidazole-containing hypoxia markers, F-misonidazole (F-MISO) has evolved as the 'gold standard' (Fig. 2). It has not yet been approved for broad use in humans. Its slow clearance, high lipophilicity, liver and gut uptake, and long uptake times prevent it from being an ideal hypoxia imaging agent.[55] With the aid of click chemistry, we have developed a novel, pharmacokinetic-optimized hypoxia tracer, HX4, which displayed the most favorable characteristics from an imaging perspective.

In pharmacokinetic distribution studies in rodents, ${ }^{18} \mathrm{~F}-\mathrm{HX} 4$ cleared predominantly via the kidneys and into the urine up to $2 \mathrm{hrs}$ post injection (Fig. 3). The blood levels also decrease rapidly over $2 \mathrm{hrs}$ indicating a rapid washout. There is relatively little uptake in the liver and GI tract, however the gall bladder did contain a small, yet noticeable portion of the tracer. In contrast, F-MISO tends to clear via the liver and GI with a much slower rate than HX4.[56] Unlike FMISO, however, HX4 does not appreciably cross the BBB. These significant changes in biodistribution and pharmacokinetic properties are largely attributed to the physiochemical properties of the triazole itself

\section{Application of Click Chemistry for Radiolabeling Improvements}

The copper-catalyzed triazole formation allows easy radiolabeling, since it is

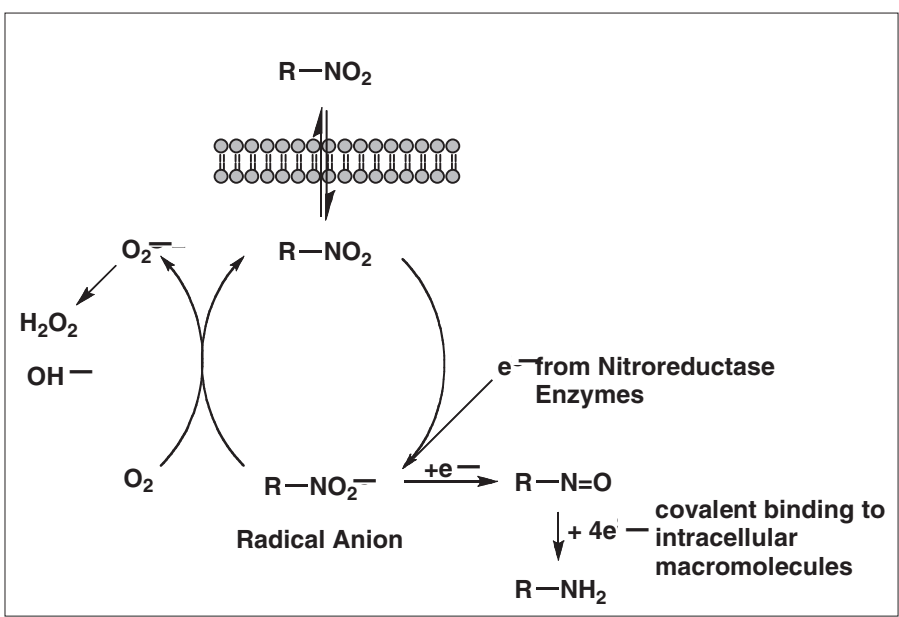

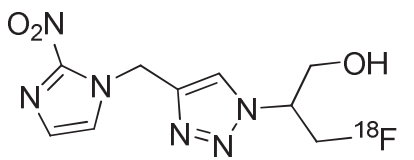

HX4
Scheme 2. Proposed mechanism of localization of 2-nitroimidazole-based hypoxia tracers.

Fig. 2. Chemical structures of ${ }^{18} \mathrm{~F}-\mathrm{MISO}$ and ${ }^{18} \mathrm{~F}-\mathrm{HX} 4$. 


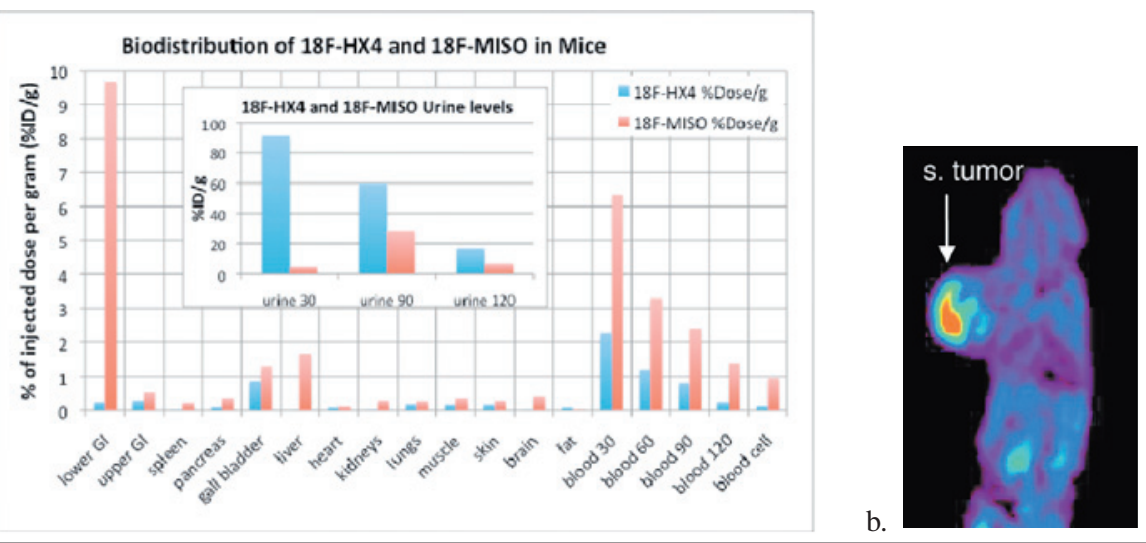

Fig. 3. (a) Biodistribution of ${ }^{18} \mathrm{~F}-\mathrm{HX} 4$ and ${ }^{18} \mathrm{~F}-\mathrm{MISO}$ in normal rodents up to 2 hrs post injection; (b) MicroPET image of ${ }^{18} \mathrm{~F}-\mathrm{HX} 4$ in a hypoxic spontaneous tumor (rasH2 mouse model), 90 min after tracer injection. The image reflects the PK blood washout profile of ${ }^{18} \mathrm{~F}-\mathrm{HX} 4$, which ultimately leads to a very clean background signal.

fast, high-yielding and highly selective, requiring minimal use of protecting groups. This is especially beneficial in case of highly functionalized molecules, such as peptides. Early reports disclosed the $\mathrm{Cu}(\mathrm{I})$ catalyzed labeling of linear peptides ${ }^{[57-59]}$ and additional reports disclosed the click labeling of RGD peptides. ${ }^{[59]}$

We have applied this technique to the development of the integrin imaging tracer ${ }^{18} \mathrm{~F}-\mathrm{RGD}-\mathrm{K} 5$, which is a cyclic pentapeptide. Integrin- $\alpha v \beta 3$ is an interesting imaging target, because this extracellular protein is not widely expressed in normal tissues, while it is over-expressed on the surface of angiogenic endothelial cells in malignant tumors. ${ }^{[60,61]}$ The non-invasive diagnostic imaging of integrin- $\alpha v \beta 3$ expression may help to identify patients who might respond favorably to anti-integrin or anti-angiogenesis treatment, and to monitor efficacy of treatment in patients whose tumors are integrin positive. ${ }^{[62]}$

Most PET tracers for the in vivo imaging of integrin expression utilize the R-G-D tripeptide motif, usually within a cyclic peptide structure. An example is galactosyl-RGD, a cyclic pentapeptide, which has been shown in humans to allow integrin imaging. ${ }^{[62-64]}$ The labeling of these molecules using 'traditional ${ }^{18} \mathrm{~F}$ chemistry is very cumbersome, requiring protecting groups and multiple chemical and purification steps. ${ }^{[65]}$

We have developed the RGD-based integrin imaging agent, ${ }^{18} \mathrm{~F}-\mathrm{RGD}-\mathrm{K} 5$, which is easy to label through click chemistry, without requiring protecting groups, by reacting ${ }^{18} \mathrm{~F}$-fluoropentyne and an azide precursor (Scheme 3). It is an analog of the known galactosyl-RGD, where the ${ }^{18} \mathrm{~F}$ propionamide linkage, which is difficult to introduce, has been replaced with an ${ }^{18} \mathrm{~F}$ alkyl triazole linkage.

${ }^{18} \mathrm{~F}$-labeling is performed on an automated synthesis module using pentyne tosylate as a precursor for ${ }^{18} \mathrm{~F}$ introduction. Galactosyl-RGD.
Reaction with anhydrous $\left[{ }^{18} \mathrm{~F}\right]$-fluoride yields $\left[{ }^{18} \mathrm{~F}\right]$-fluoropentyne, which was distilled into a vial containing the RGDcontaining azide precursor and the copper catalyst in aqueous $\mathrm{EtOH}$, to initiate the $\mathrm{Cu}(\mathrm{I})$-catalyzed click reaction. After reacting for $30 \mathrm{~min}$, the crude reaction mixture was purified by reverse phase HPLC. The total process time was 90 min., i.e. less than one half-life.

${ }^{18} \mathrm{~F}-\mathrm{RGD}-\mathrm{K} 5$ binds to integrin- $\alpha \mathrm{v} \beta 3$ with high affinity (integrin- $\alpha v \beta 3 \mathrm{Kd}=7.9$
nM, 'inverse' Surface Plasmon Resonance (SPR) assay, which utilizes immobilized RGD peptide), similar to that of RGDfK $(\mathrm{Kd}=6.6 \mathrm{nM})$. Not surprisingly, it also possesses similar integrin sub-type selectivity.

${ }^{18} \mathrm{~F}-\mathrm{RGD}-\mathrm{K} 5$ washes out quickly from both blood and muscle, with a pronounced renal clearance (Fig. 4). It is metabolically stable in mice and humans. The tracer localized in vivo in integrin expressing tumors, and the uptake can be blocked with RGD-fK. Fig. 4a shows tumor uptake of ${ }^{18} \mathrm{~F}$-RGD-K5 and ${ }^{18} \mathrm{~F}$-Galacto-RGD in an immune-compromised mouse, carrying the U87MG tumor xenograph.

\section{Conclusion}

Click chemistry was developed with the intention of focusing efforts on practical, reliable chemistry for making a wide variety of compounds. Others and we have demonstrated this approach to be useful for the discovery of new radiotracers and for their optimization with respect to binding affinity, biodistribution and pharmacokinetic profile and ease of radiosynthesis.

Received: January 18, 2010

[1] H. C. Kolb, M. G. Finn, K. B. Sharpless, Angew. Chem. Int. Ed. 2001, 40, 2004.

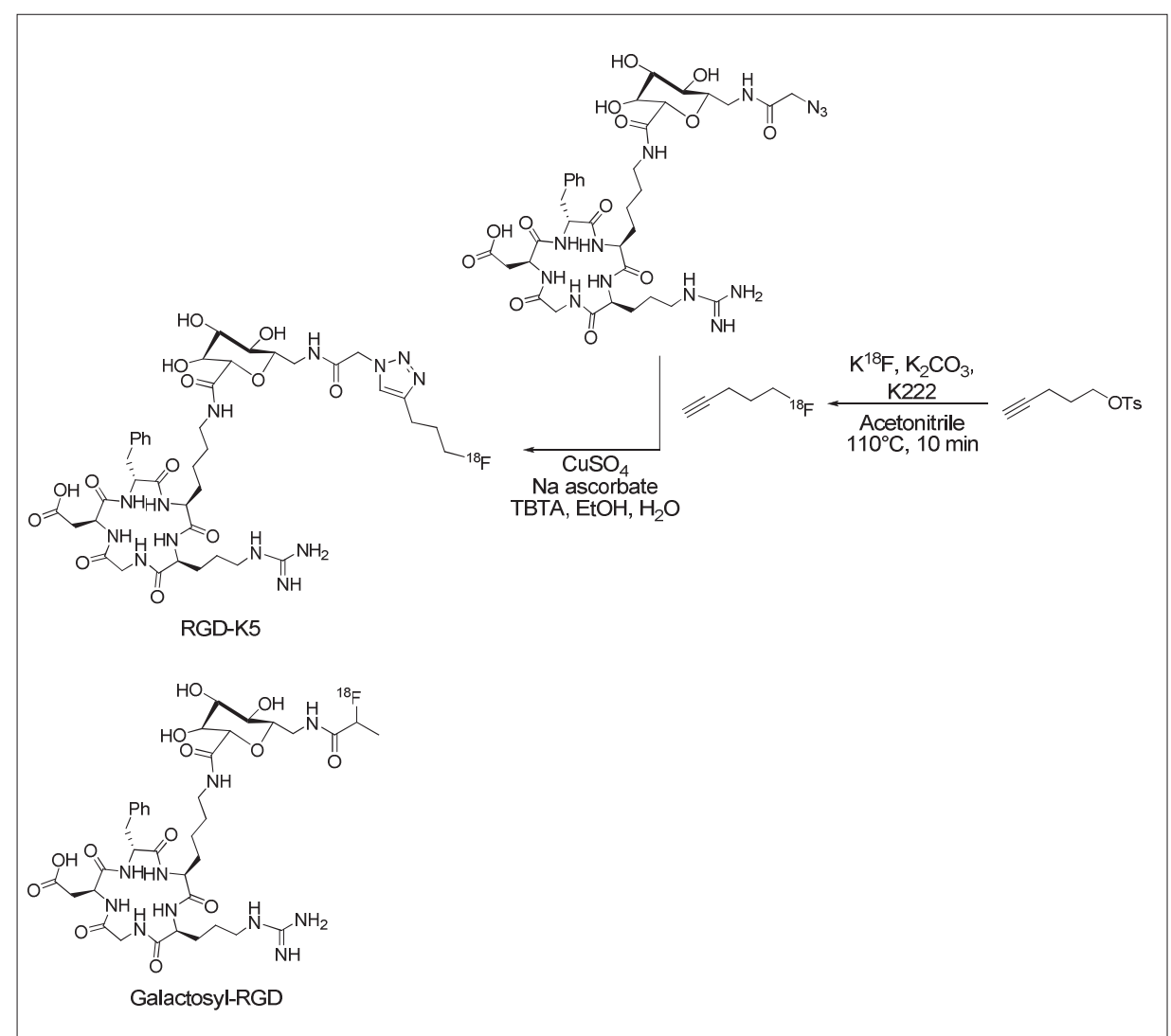

Scheme 3. Radiosynthesis of ${ }^{18} \mathrm{~F}-\mathrm{RGD}-\mathrm{K} 5$ using click chemistry and the chemical structure of 

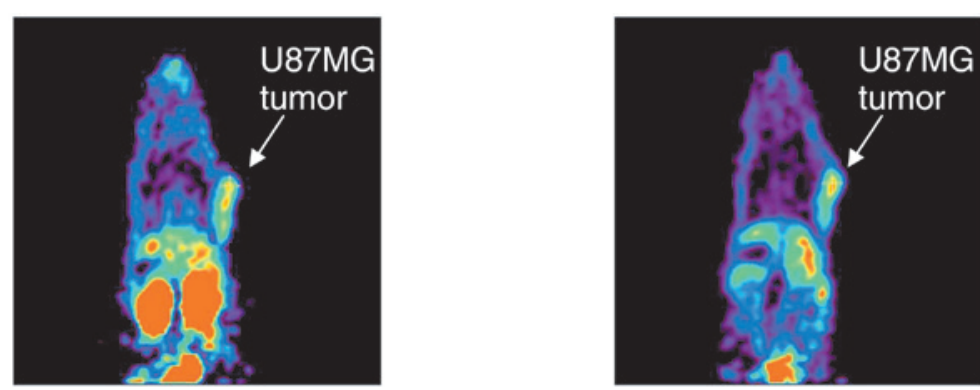

${ }^{18}$ F-RGD-K-5 U87 (90 min p.i.)

${ }^{18}$ F-Galacto-RGD U87 (90 min p.i.)
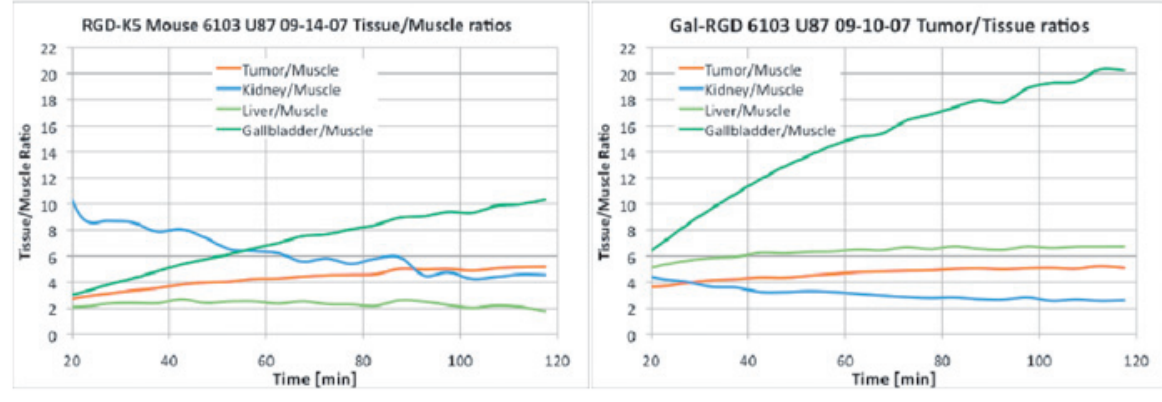

Fig. 4. (a) PET images 90 post injection with ${ }^{18} \mathrm{~F}-\mathrm{RGD}-\mathrm{K} 5$ and ${ }^{18} \mathrm{~F}-$-Galactosyl-RGD, respectively, in immune-compromised mouse, carrying the U87MG tumor xenograft (right side of each image); (b) dynamic tissue/muscle ratios of tracer uptake. ${ }^{18} \mathrm{~F}-\mathrm{RGD}-\mathrm{K} 5$ displays similar tumor/muscle ratios as ${ }^{18} \mathrm{~F}$-Galactosyl-RGD, but smaller liver/muscle and gallbladder/muscle ratios, combined with higher kidney/muscle ratios, demonstrating preferred renal clearance.

[2] H. C. Kolb, K. B. Sharpless, Drug Discov. Today 2003, 8, 1128

[3] C. W. Tornøe, C. Christensen, M. Meldal, J. Org. Chem. 2002, 67, 3057.

[4] F. Amblard, J. H. Cho, R. F. Schinazi, Chem. Rev. 2009, 109, 4207.

[5] J. E. Hein, J. C. Tripp, L. B. Krasnova, K. B. Sharpless, V. V. Fokin, Angew. Chem. Int. Ed. 2009, 48, 8018.

[6] G. Cravotto, V. V. Fokin, D. Garella, A. Binello, L. Boffa, A. Barge, J. Comb. Chem. 2009, 12, 13.

[7] A. Chanda, V. V. Fokin, Chem. Rev. 2009, 109, 725 .

[8] M. Meldal, C. W. Tornøe, Chem. Rev. 2008, 108, 2952.

[9] V. V. Rostovtsev, L. G. Green, V. V. Fokin, K. B. Sharpless, Angew. Chem. Int. Ed. 2002, 41, 2596.

[10] G. C. Tron, T. Pirali, R. A. Billington, P. L. Canonico, G. Sorba, A. A. Genazzani, Med. Res. Rev. 2008, 28, 278.

[11] A. D. Moorhouse, J. E. Moses, ChemMedChem 2008, 3, 715 .

[12] I. S. Bennett, G. Brooks, N. J. Broom, S. H. Calvert, K. Coleman, I. Francois, J. Antibiot. (Tokyo) 1991, 44, 969.

[13] I. Bennett, N. J. Broom, G. Bruton, S. Calvert, B. P. Clarke, K. Coleman, R. Edmondson, P. Edwards, D. Jones, N. F. Osborne, G. Walker, J. Antibiot. (Tokyo) 1991, 44, 331.

[14] W. G. Lewis, L. G. Green, F. Grynszpan, Z Radic, P. R. Carlier, P. Taylor, M. G. Finn, K. B. Sharpless, Angew. Chem. Int. Ed. 2002, 41, 1053.

[15] R. Manetsch, A. Krasinski, Z. Radic, J. Raushel, P. Taylor, K. B. Sharpless, H. C. Kolb, J. Am. Chem. Soc. 2004, 126, 12809.

[16] A. Krasinski, Z. Radic, R. Manetsch, J. Raushel, P. Taylor, K. B. Sharpless, H. C. Kolb, J. Am. Chem. Soc. 2005, 127, 6686.

[17] V. P. Mocharla, B. Colasson, L. V. Lee, S. Roper, K. B. Sharpless, C. H. Wong, H. C. Kolb, Angew. Chem. Int. Ed. 2004, 44, 116.
[18] M. Whiting, J. Muldoon, Y. C. Lin, S. M. Silverman, W. Lindstrom, A. J. Olson, H. C. V. V. Fokin, Angew. Chem. Int. Ed. 2006, 45, 1435 .

[19] A. Brik, C. Y. Wu, C. H. Wong, Org. Biomol. Chem. 2006, 4, 1446.

[20] M. E. Phelps, Proc. Natl. Acad. Sci. USA 2000, 97, 9226.

[21] B. M. Seddon, P. Workman, Br. J. Radiol. 2003, 76, S128.

[22] J. Wang, L. Maurer, Curr. Top. Med. Chem. 2005, 5, 1053.

[23] N. Gupta, P. M. Price, E. O. Aboagye, Eur. J. Cancer. 2002, 38, 2094.

[24] G. I. Bell, C. F. Burant, J. Takeda, G. W. Gould, J. Biol. Chem. 1993, 268, 19161.

[25] R. S. Brown, J. Y. Leung, P. V. Kison, K. R. Zasadny, A. Flint, R. L. Wahl, J. Nucl. Med. 1999, 40, 556.

[26] G. J. Kelloff, J. M. Hoffman, B. Johnson, H. I. Scher, B. A. Siegel, E. Y. Cheng, B. D. Cheson, J. O'Shaughnessy, K. Z. Guyton, D. A. Mankoff, L. Shankar, S. M. Larson, C. C. Sigman, R. L. Schilsky, D. C. Sullivan, Clin. Cancer Res. 2005, 11, 2785.

[27] O. Warburg, K. Posener, Biochem. Zeitschrift 1924, 152, 309

[28] J. Czernin, M. E. Phelps, Annu. Rev. Med. 2002, 53,89 .

[29] L. Varagnolo, M. P. Stokkel, U. Mazzi, E. K. Pauwels, Nucl. Med. Biol. 2000, 27, 103.

[30] I. Penuelas, J. Boan, J. M. Marti-Climent, B. Sangro, G. Mazzolini, J. Prieto, J. A. Richter, Mol. Imaging Biol. 2004, 6, 225.

[31] R. G. Blasberg, J. Gelovani, Mol. Imaging 2002, $1,280$.

[32] R. Blasberg, Eur. J. Cancer 2002, 38, 2137.

[33] H. F. VanBrocklin, Current Radiopharmaceuticals 2008, 1,2 .

[34] D. Maclean, J. P. Northrop, H. C. Padgett, J. C. Walsh, Mol. Imaging Biol. 2003, 5, 304. Kolb, M. G. Finn, K. B. Sharpless, J. H. Elder,
[35] K. Serdons, A. Verbruggen, G. M. Bormans, Methods 2009, 48, 104.

[36] D. J. McCarthy, C. Halldin, J. D. Andersson, M E. Pierson, Апnи. Rep. Med. Chem. 2009, 44, 501.

[37] J. S. Fowler, A. P. Wolf, Acc. Chem. Res. 1997, $30,181$.

[38] K. Serdons, A. Verbruggen, G. Bormans, $J$. Nucl. Med. 2008, 49, 2071

[39] W. L. Chiang, S. C. Chu, S. S. Yang, M. C. Li, J. C. Lai, S. F. Yang, H. L. Chiou, Y. S. Hsieh, Cancer Lett. 2002, 188, 199.

[40] S. Parkkila, A. K. Parkkila, T. Juvonen, V. P. Lehto, H. Rajaniemi, Histochem. J. 1995, 27 , 133.

[41] C. T. Supuran, M. A. Ilies, A. Scozzafava, Eur J. Med. Chem. 1998, 33, 739 .

[42] A. Jain, S. G. Huang, G. M. Whitesides, J. Am Chem. Soc. 1994, 116, 5057.

[43] R. F. Chen, J. C. Kernohan, J. Biol. Chem. 1967, $242,5813$.

[44] C. V. Gay, W. J. Mueller, J. Histochem Cytochem. 1973, 21, 693.

[45] E. R. Swenson, C. G. Rhodes, L. Araju, V. W. Pike, D. Le Bars, R. M. Effros, J. M. B. Hughes, Physiologist 1989, 32, 210.

[46] W. S. Sly, P. Y. Hu, Annu. Rev. Biochem. 1995 64,375 .

[47] G. E. Adams, Cancer 1981, 48, 696.

[48] J. E. Moulder, S. Rockwell, Int. J. Radiat Oncol. Biol. Phys. 1984, 10, 695.

[49] M. Nordsmark, M. Overgaard, J. Overgaard, Radiother. Oncol. 1996, 41, 31.

[50] S. B. Reddy, S. K. Williamson, Expert Opin. Investig. Drugs 2009, 18, 77.

[51] M. Takasawa, R. R. Moustafa, J. C. Baron, Stroke 2008, 39, 1629.

[52] L. Kalinowski, L. W. Dobrucki, D. F. Meoli, D. P. Dione, M. M. Sadeghi, J. A. Madri, A. J. Sinusas, J. Appl. Physiol. 2008, 104, 1504.

[53] B. A. Teicher, J. S. Lazo, A. C. Sartorelli, Cancer Res. 1981, 41, 73.

[54] M. Piert, H. J. Machulla, M. Picchio, G. Reischl, S. Ziegler, P. Kumar, H. J. Wester, R. Beck, A. J. McEwan, L. I. Wiebe, M. Schwaiger, J. Nucl. Med. 2005, 46, 106.

[55] G. R. Laking, P. M. Price, Br. J. Radiol. 2003, 76, S50.

[56] P. Mahy, M. De Bast, T. de Groot, A Cheguillaume, J. Gillart, K. Haustermans, D. Labar, V. Gregoire, Radiother. Oncol. 2008, 89, 353.

[57] J. Marik, J. L. Sutcliffe, Tetrahedron Lett. 2006 $47,6681$.

[58] M. Glaser, M. Morrison, M. Solbakken, J. Arukwe, H. Karlsen, U. Wiggen, S. Champion, G. M. Kindberg, A. Cuthbertson, Bioconjug. Chem. 2008, 19, 951

[59] Z. B. Li, Z. Wu, K. Chen, F. T. Chin, X. Chen, Bioconjug. Chem. 2007, 18, 1987.

[60] E. Garanger, D. Boturyn, P. Dumy, Anticancer Agents Med. Chem. 2007, 7, 552.

[61] M. Schottelius, B. Laufer, H. Kessler, H. J. Wester, Acc. Chem. Res. 2009, 42, 969.

[62] A. J. Beer, R. Haubner, M. Sarbia, M. Goebel, S. Luderschmidt, A. L. Grosu, O. Schnell, M. Niemeyer, H. Kessler, H. J. Wester, W. A. Weber, M. Schwaiger, Clin. Cancer Res. 2006, 12,3942 .

[63] R. Haubner, W. A. Weber, A. J. Beer, E Vabuliene, D. Reim, M. Sarbia, K. F. Becker, M. Goebel, R. Hein, H. J. Wester, H. Kessler, M. Schwaiger, PLoS Med. 2005, 2, e70.

[64] A. J. Beer, R. Haubner, M. Goebel, S. Luderschmidt, M. E. Spilker, H. J. Wester, W. A. Weber, M. Schwaiger, J. Nucl. Med. 2005, 46, 1333.

[65] X. Chen, M. Tohme, R. Park, Y. Hou, J. R. Bading, P. S. Conti, Mol. Imaging 2004, 3, 96. 